\title{
Variation in Immunoreactive Trypsinogen Concentrations Among Michigan Newborns and Implications for Cystic Fibrosis Newborn Screening
}

\author{
Steven J. Korzeniewski, Ms, MA, ${ }^{1}$ William I. Young, PhD, ${ }^{1}$ Harry C. Hawkins, Bs, ${ }^{1}$ \\ Kevin Cavanagh, PhD, ${ }^{1}$ Samya Z. Nasr, $\mathrm{MD}^{2}{ }^{2}$ Carrie Langbo, MS, cGc, ${ }^{1 \star}$ Kelly R. TenEyck, Ms, ${ }^{1}$ \\ Scott D. Grosse, $\mathrm{PhD},{ }^{3}$ Mary Kleyn, $\mathrm{MS}^{1}{ }^{1}$ and Violanda Grigorescu, $\mathrm{MD}, \mathrm{MSPH}^{1}$
}

\begin{abstract}
Summary. Objective: To investigate variation in immunoreactive trypsinogen (IRT) concentrations by race, sex, birth weight, and gestational age and their implications for the use of percentile-based cutoffs for cystic fibrosis (CF) newborn screening (NBS) programs. Patients and Methods: This cross-sectional population-based study of resident infants screened in Michigan investigates associations between demographic and perinatal variables and IRT concentrations after controlling for covariates. This study also analyzed how 96th and 99.8th IRT concentration percentiles values calculated by Michigan NBS vary by demographic and perinatal factors. Characteristics of infants having high ( $\geq 99$.8th percentile) IRT concentrations and negative DNA tests are also explored. Results: IRT mean concentrations and percentiles vary significantly by race, birth weight, gestational age, and to a lesser degree by sex. The greatest variation in mean IRT concentrations was observed among racial categories; black infants had an adjusted mean concentration of $36 \mathrm{ng} / \mathrm{ml}$ and Asian/Pacific Islander infants had a mean concentration of $25 \mathrm{ng} / \mathrm{ml}$ compared to an average concentration of $28 \mathrm{ng} / \mathrm{ml}$ in white infants and infants of other races. Conclusions: Variation in IRT concentrations resulted in the over-representation of certain groups referred for secondary testing, particularly referrals for sweat testing based on very high ( $\geq 99.8$ th percentile) concentrations alone, which is no longer recommended in Michigan. Further research may be warranted to evaluate initial IRT cutoffs used for CF NBS. Pediatr Pulmonol. 2011; 46:125-130. ๑ 2011 Wiley-Liss, Inc.
\end{abstract}

Key words: cystic fibrosis; newborn screening; immunoreactive trypsinogen.

Funding source: Michigan Cystic Fibrosis Newborn Screening Research Subcommittee.

\section{INTRODUCTION}

Cystic fibrosis (CF), an autosomal recessive genetic disorder caused by mutations of the $\mathrm{CF}$ transmembrane conductance regulator $(C F T R)$ gene, ${ }^{1}$ can be screened for in newborn infants by measurement of elevated immunoreactive trypsinogen (IRT) concentrations. ${ }^{2}$ Extensive research conducted since the early 1980s including cohort studies, trials, and economic analyses, has demonstrated beneficial outcomes associated with newborn screening (NBS) for $\mathrm{CF}^{3,4}$ These findings, along with expert recommendations, led to the inclusion of $\mathrm{CF}$ in the recommended NBS core panel in the United States in 2005. ${ }^{5}$

The Michigan (MI) NBS program began screening for CF October 2007 using a protocol that measures IRT concentrations from newborn dried blood spots to identify infants at increased risk of CF for DNA testing. Further analysis, using a panel of $40 \mathrm{CF}$ mutations, is completed for infants having IRT concentrations $\geq 96$ th percentile. In the absence of an identified CFTR mutation, as a fail-safe measure, sweat testing is recommended for infants having IRT concentrations $\geq 99$.8th percentile.

\footnotetext{
${ }^{1}$ Michigan Department of Community Health, Lansing, Michigan.

${ }^{2}$ University of Michigan, Ann Arbor, Michigan.

${ }^{3}$ Centers for Disease Control and Prevention, Atlanta, Georgia.
}

The authors have no financial disclosures or conflicts of interest to disclose.

Disclaimer: The findings and conclusions in this report are those of the authors and do not necessarily represent the official position of the Centers for Disease Control and Prevention.

Human subjects: This study was approved by the MDCH Institutional Review Board.

\footnotetext{
*Correspondence to: Carrie Langbo, MS, CGC, BioTrust Community Engagement Coordinator, Division of Genomics, Perinatal Health and Chronic Disease Epidemiology Bureau of Epidemiology, Michigan Department of Community Health, 201 Capital View, 4-012, Lansing MI 48906. E-mail: langboc@michigan.gov
}

Received 17 December 2009; Revised 18 June 2010; Accepted 19 June 2010.

DOI 10.1002/ppul.21330

Published online in Wiley Online Library

(wileyonlinelibrary.com). 
During the first year of CF screening in MI, members of the MI NBS program and the NBS CF Advisory Committee reported concern about the number of infants with high IRT concentrations and negative DNA tests in the neonatal intensive care unit (NICU). This observation was consistent with previous reports of elevated IRT concentrations in blacks and in premature/low birth weight infants; ${ }^{6-11,15-17}$ however, past studies failed to control for the impact of potential confounders meaning questions remain about whether variation by demographic/perinatal factors could account for the rate of high IRT concentrations among NICU infants.

This study was designed to analyze associations between IRT concentrations and demographic and perinatal characteristics among resident infants screened in Michigan to better understand factors that impact referral rates for CF secondary testing. The aim of this study was to garner information that may inform improvements in the CF NBS process and avoid unnecessary medicalization of families.

\section{METHODS}

Dried blood spots are obtained from newborns in MI via a heel prick, usually between 24 and $36 \mathrm{hr}$ of life. Blood spots are stored on filter paper cards that also include demographic information on both the infant and the mother. NBS cards are sent to the Bureau of Laboratories, Division of Chemistry and Toxicology housed within the State Laboratory at the Michigan Department of Community Health (MDCH) for analysis. IRT testing is performed at the State newborn screening laboratory in Lansing Michigan using an AutoDelfia time resolved fluoroimmunoassay (Perkin Elmer Life Sciences, Inc., Newborn, Michigan). DNA mutation analysis of the CFTR gene is performed using a CFTR InPlex ${ }^{\text {TM }}$ ASR method (Third Wave Technology, Inc., Michigan). Screening data are stored in a Laboratory Information Management System (LIMS) created by Perkin Elmer Life Sciences, Inc.

IRT concentrations were measured from the newborn dried blood spots collected from resident births occurring in MI during the first year of CF screening (October 1, 2007 through September 30, 2008). Infant demographic and perinatal data were obtained from the NBS card. Hispanic ethnicity data were not evaluated in this study due to concerns regarding data quality stemming from the extent of missing information. Medical management data

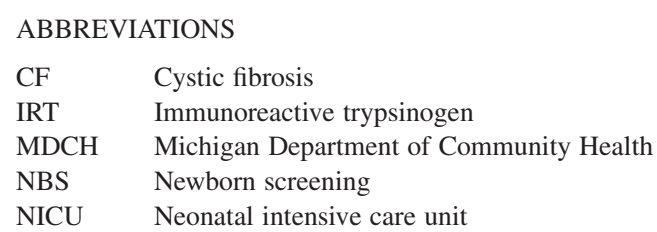

maintained by the MI NBS Follow-up Program were used to differentiate diagnosed $\mathrm{CF}$ cases from carriers and infants with high IRT concentrations and negative DNA tests.

IRT percentile cutoff values calculated in Michigan's screening algorithm to identify infants for DNA mutation testing (96\%) or referral for sweat testing in the absence of mutations (99.8\%) are reported in total and among selected strata. Crude and adjusted generalized linear models of the association between demographic variables and IRT concentrations were constructed. Adjusted models included the following demographic and perinatal variables: sex, race, birth weight, gestational age, and age at specimen collection (age at specimen collection data not reported). To avoid multicollinearity, gestational age and birth weight were assessed independently in adjusted models; although the effects of each in the same adjusted model were also evaluated. Generalized linear models were selected because our objective was to assess variation in IRT concentrations rather than modeling the odds of a positive CF screen as recently done by Giusti et al. ${ }^{8}$ We report concentration values rather than odds in hopes that other NBS programs may better evaluate our results in relation to their practices, particularly in regard to $\mathrm{CF}$ screening cutoff value selection.

Analyses of mean IRT concentrations and percentile values excluded confirmed cases because our objective was to assess IRT variation unrelated to the CF disease process. Finally, we report the descriptive characteristics of infants having increased IRT concentrations and of confirmed cases in comparison to the general population to better understand the implications of variation in IRT concentrations by demographic and perinatal risk factors.

\section{RESULTS}

A total of 118,775 resident infants were screened in MI during the study period. Of those, $37(1: 3,198)$ were diagnosed with CF. Table 1 reports the IRT concentration percentile values calculated to select infants for DNA testing ( $\geq 96$ th percentile) and for sweat testing for infants having no mutations identified by the DNA test $(\geq 99.8$ th percentile); crude and adjusted least squares mean concentrations among strata of selected demographic and perinatal factors are also reported. Black infants and those born with very low birth weight $(<1,500 \mathrm{~g})$ or very preterm $(<32$ weeks gestational age) have significantly elevated IRT percentile concentrations relative to the percentile concentrations among the general population.

IRT concentrations varied significantly by each factor in both crude and adjusted models; however, the magnitude of variation was greatest among racial categories in both. After adjustment, black infants had a mean IRT concentration of $36 \mathrm{ng} / \mathrm{ml}$ and Asian/Pacific Islander infants had a mean concentration of $25 \mathrm{ng} / \mathrm{ml}$ compared 
TABLE 1-Immunoreactive Trypsinogen Concentration Percentile Values and Crude/Adjusted Least Squares Mean Concentrations, by Demographic and Perinatal Risk Factors, MI NBS, October 2007 to October 2008

\begin{tabular}{|c|c|c|c|c|c|c|c|c|}
\hline \multirow{4}{*}{$\begin{array}{l}\text { Variables and categories } \\
\text { Race }\end{array}$} & \multirow{4}{*}{$\mathrm{N}$} & \multirow{4}{*}{$\%$} & \multicolumn{6}{|c|}{ IRT concentration $(\mathrm{ng} / \mathrm{ml})$} \\
\hline & & & \multicolumn{2}{|c|}{ Percentile values } & \multicolumn{4}{|c|}{ Least squares means } \\
\hline & & & 96th & 99.8th & \multicolumn{2}{|c|}{ Crude } & \multicolumn{2}{|c|}{ Adjusted $^{1}$} \\
\hline & & & & & & & & \\
\hline White & 75,563 & 70.65 & 55 & 109 & 26.0 & $<0.0001$ & 27.9 & $<0.0001$ \\
\hline Black & 21,144 & 19.77 & 76 & 133 & 34.0 & & 35.8 & \\
\hline American Indian & 541 & 0.51 & 57 & 113 & 26.6 & & 28.6 & \\
\hline Asian/Pacific Islander & 2,540 & 2.37 & 50 & 92 & 22.9 & & 24.8 & \\
\hline Arab descent & 2,710 & 2.53 & 58 & 110 & 27.1 & & 28.9 & \\
\hline Multiracial & 4,461 & 4.17 & 61 & 117 & 27.8 & & 29.7 & \\
\hline \multicolumn{9}{|l|}{ Gestational age (weeks) } \\
\hline$<32$ & 1,780 & 1.55 & 92 & 373 & 34.3 & $<0.0001$ & 33.1 & 0.0002 \\
\hline $32-36$ & 9,991 & 8.7 & 62 & 161 & 28.8 & & 28.2 & \\
\hline$\geq 37$ & 103,074 & 89.75 & 59 & 114 & 27.3 & & 27.2 & \\
\hline \multicolumn{9}{|l|}{ Birth weight (g) } \\
\hline$<1,500$ & 1,609 & 1.38 & 96 & 344 & 35.0 & $<0.0001$ & 33.7 & $<0.0001$ \\
\hline $1,500-2,499$ & 7,823 & 6.7 & 66 & 157 & 29.6 & & 28.5 & \\
\hline $2,500-3,999$ & 96,432 & 82.64 & 60 & 115 & 27.5 & & 27.2 & \\
\hline$>4,000$ & 10,825 & 9.28 & 56 & 100 & 25.7 & & 26.3 & \\
\hline \multicolumn{9}{|l|}{ Sex } \\
\hline Female & 57,506 & 48.91 & 61 & 118 & 28.0 & $<0.0001$ & 29.7 & $<0.0001$ \\
\hline Male & 60,073 & 51.09 & 59 & 115 & 27.0 & & 28.9 & \\
\hline Total & 118,775 & 100 & 60 & 118 & - & - & - & - \\
\hline
\end{tabular}

Missing data are as follows: race: $\mathrm{n}=11,361$, gestational age: $\mathrm{n}=1,631$, birth weight: $\mathrm{n}=3,475$.

${ }^{1}$ Adjusted for other covariates listed in this table. To avoid multicollinearity, birthweight, and gestational age were assessed independently in adjusted models; both remained significantly associated with IRT when added to the same model adjusted for other factors.

to an average concentration of $\sim 28 \mathrm{ng} / \mathrm{ml}$ in white infants and those of other races. Infants born $<32$ weeks of gestational age and those born weighing $<1,500 \mathrm{~g}$ also had greater mean IRT concentrations compared to infants born at term and/or of normal birth weight, respectively. Adjustment attenuated the association between IRT and gestational age, and to a lesser degree between birth weight and IRT concentration; however, the associations remained significant and linear. The associations between preterm birth and low birth weight and IRT concentration are driven primarily by high IRT concentrations in very low birth weight $(<1,500 \mathrm{~g})$ and very preterm infants $(<28$ weeks). However, the IRT concentrations in moderately low birth weight $(1,500-2,499 \mathrm{~g})$ and moderately preterm ( 32 to $<37$ weeks gestational age) infants are statistically significantly greater than in normal birth weight and term infants, respectively (one point adjusted difference in least squares mean IRT concentrations), although the clinical significance is arguable. While the least squares mean concentration of IRT differs statistically by sex, the magnitude of the difference is negligible.

Table 2 reports the demographic characteristics of infants having increased IRT concentrations relative to their distribution in the general population and among confirmed cases. The proportion of black infants having IRT concentrations $\geq 96$ th percentile and is more than double the proportion of black infants in the general population ( $43 \%$ vs. $20 \%$, respectively). Infants born very preterm or very low birth weight are nearly threefold overrepresented among infants with raised IRT concentrations ( $\geq 96$ th percentile) relative to the general population. While white infants and those born at term and/or of normal birth weight are at greater risk for CF (overrepresented among cases), they are under-sampled for secondary testing for CF. Variation in the range of IRT concentrations particularly impacts the demographic distribution of infants having IRT concentrations $\geq 99.8$ th percentile and no identified CF mutation. Specifically, the proportions of infants born very preterm or very low birth weight that undergo sweat chloride testing based on IRT alone are more than 15 times greater than their respective proportions in the general population; although absolute numbers of these infants are small. Black infants referred for sweat chloride testing based on IRT alone remain nearly twofold over-represented relative to the general population as well.

\section{DISCUSSION}

Our study indicates that percentiles calculated to identify infants at risk of CF for DNA mutation analysis or sweat testing based on IRT alone vary widely by 
TABLE 2-Descriptive Characteristics of Infants With Increased IRT Concentrations by CF Diagnosis Status Relative to the General Population, MI NBS, October 1, 2007 to September 30, 2008

\begin{tabular}{|c|c|c|c|c|c|c|c|c|}
\hline \multirow[b]{3}{*}{ Variables and categories } & \multicolumn{2}{|c|}{ General population } & \multicolumn{4}{|c|}{ CF not detected (initial NBS) } & \multicolumn{2}{|c|}{ Detected CF cases } \\
\hline & \multirow[b]{2}{*}{$\mathrm{N}$} & \multirow[b]{2}{*}{$\%$} & \multicolumn{2}{|c|}{$\geq 96$ th percentile IRT } & \multicolumn{2}{|c|}{$\begin{array}{l}\geq 99.8 \text { th percentile } \\
\text { IRT, no CF mutation }\end{array}$} & \multirow[b]{2}{*}{$\mathrm{N}$} & \multirow[b]{2}{*}{$\%$} \\
\hline & & & $\mathrm{N}$ & $\%$ & $\mathrm{~N}$ & $\%$ & & \\
\hline \multicolumn{9}{|l|}{ Race } \\
\hline White & 75,563 & 70.7 & 2,311 & 48.9 & 46 & 55.4 & 31 & 88.6 \\
\hline Black & 21,144 & 19.8 & 2,024 & 42.9 & 32 & 38.6 & 3 & 8.6 \\
\hline American Indian & 541 & 0.5 & 21 & 0.4 & - & - & - & - \\
\hline Asian/Pacific Islander & 2,540 & 2.4 & 57 & 1.2 & 1 & 1.2 & 1 & 2.9 \\
\hline Arab descent & 2,710 & 2.5 & 101 & 2.1 & - & - & - & - \\
\hline Multiracial & 4,461 & 4.2 & 209 & 4.4 & 4 & 4.8 & - & - \\
\hline \multicolumn{9}{|l|}{ Gestational age (weeks) } \\
\hline$<32$ & 1,780 & 1.6 & 201 & 4.0 & 39 & 40.6 & 1 & 2.8 \\
\hline $32-36$ & 9,991 & 8.7 & 460 & 9.2 & 23 & 24.0 & 2 & 5.6 \\
\hline$\geq 37$ & 103,074 & 89.8 & 4,333 & 86.8 & 34 & 35.4 & 33 & 91.7 \\
\hline \multicolumn{9}{|l|}{ Birth weight (g) } \\
\hline$<1,500$ & 1,609 & 1.4 & 188 & 3.7 & 30 & 31.9 & 1 & 2.7 \\
\hline $1,500-2,499$ & 7,823 & 6.7 & 450 & 8.9 & 21 & 22.3 & 4 & 10.8 \\
\hline $2,500-3,999$ & 96,432 & 82.6 & 4,088 & 80.5 & 40 & 42.6 & 30 & 81.1 \\
\hline$>4,000$ & 10,825 & 9.3 & 353 & 7.0 & 3 & 3.2 & 2 & 5.4 \\
\hline \multicolumn{9}{|l|}{ Sex } \\
\hline Female & 57,506 & 48.9 & 2,639 & 51.9 & 35 & 39.3 & 20 & 54.1 \\
\hline Male & 60,073 & 51.1 & 2,447 & 48.1 & 54 & 60.7 & 17 & 46.0 \\
\hline Total & 118,775 & 100 & 5,158 & 100 & 96 & 100 & 37 & 100 \\
\hline
\end{tabular}

Missing data are as follows: race: $\mathrm{n}=11,361$, gestational age: $\mathrm{n}=1,631$, birth weight: $\mathrm{n}=3,475$.

demographic and perinatal factors, as do mean concentrations. While variation in mean IRT concentrations is most pronounced among racial categories, the range of IRT percentile concentrations is greatest among very low birth weight and very preterm infants. The 99.8th percentile of IRT concentrations among very preterm $(373 \mathrm{ng} / \mathrm{ml})$ and very low birth weight $(334 \mathrm{ng} / \mathrm{ml})$ infants is more than twice that of the general population $(116 \mathrm{ng} /$ $\mathrm{ml})$. The range in both crude and adjusted least squares mean concentrations is greatest among racial strata; our study observed an 11 point difference in mean concentrations between black and Asian/Pacific Islander infants.

Failure to account for variation in IRT concentrations in the calculation of the 96th and 99.8th percentile cutoffs resulted in over-sampling of infants at lesser risk of $\mathrm{CF}$ for DNA mutation analysis and for sweat chloride testing based on high IRT alone during the first year of CF NBS in MI. This was true for black infants in general, and particularly for infants of very low birth weight or born very preterm. While it might seem ideal to adjust percentilebased cutoffs by demographic or perinatal factors, as has been done for certain non-CF protocols in selected prenatal screening programs ${ }^{13}$ the utility of adjusted cutoffs for CF NBS is arguable and not supported by our study findings. US NBS programs have traditionally avoided use of gestational age for setting cutoffs because of concerns about missing and unreliable information. The use of racial identification to target NBS was abandoned by most US NBS programs out of concerns over data reliability, logistics, and ethical considerations. ${ }^{14}$ However, our concern regarding adjusted cutoffs is not based on data quality, logistical, or ethical considerations.

Our results indicate that if the 96th IRT percentile had been adjusted for race alone then two of the three black infants diagnosed with $\mathrm{CF}$ would have been missed as their initial IRT concentrations were below $76 \mathrm{ng} / \mathrm{ml}$, the adjusted 96th percentile cutoff for black infants. This provides strong justification for not adjusting IRT percentiles by race alone. If the initial percentile cutoff had been adjusted by birth weight or gestational age then all identified cases would have been detected and the number referred for DNA mutation analysis or sweat chloride testing based on high IRT alone would have been reduced. These results highlight the complexities of adjusting $\mathrm{CF}$ NBS IRT percentile cutoffs; we recommend careful consideration of the potential benefit, if any, of adjustment in this context. If adjustment is deemed desirable then birth weight and/or gestational age should be considered as optimal adjustment factors based on the over-representation of very low birth weight and very premature infants among infants referred for DNA mutation analysis or sweat chloride testing based on high IRT alone.

While over-sampling of infants at lesser risk of CF occurred both in regard to selection for DNA mutation 
analysis and for sweat chloride testing based on very high IRT alone ( $>99.8$ th percentile) in our study, the latter is most problematic. DNA mutation analysis is performed using dried blood spots collected for the initial screen meaning no follow-up visits are required and parents are accordingly unaware of their child's sample being referred for further analysis. Thus, the potential benefit of adjusting the 96th percentile cutoff is to cut costs by avoiding a few DNA mutation tests. Given the small number of mutation analyses conducted annually for CF NBS in Michigan $(\sim 5,000)$, savings per 96th percentile adjustment would be minimal at best and likely not worth the investment of capital necessary to devise and test an appropriate adjustment strategy. Further, the second tier DNA mutation analysis that follows an elevated IRT concentration accounts for the over-sampling of lesser risk infants. For example, the proportion of black infants referred for sweat chloride testing based on DNA mutation analysis (17.7\%) is consistent with their representation in the general population (19.7\%). Thus, the primary issue identified in this study is the questionable utility of referral for sweat chloride testing based on high IRT alone.

Sweat chloride testing requires a follow-up visit, likely causes parental anxiety, ${ }^{12}$ and places considerable stress on infants. Thus, over-sampling of infants at lesser risk of $\mathrm{CF}$ for sweat chloride testing based on IRT alone disproportionately burdens Black and particularly critically ill infants born of very low birth weight and/or very preterm. Considering the difficulties associated with sweat testing these vulnerable and unstable infants and that none of them were confirmed as having CF, it does not appear to be beneficial or cost effective to refer for confirmatory testing based on high IRT ( $\geq 99.8$ th percentile) alone. Based on these findings and in consult with other NBS programs, the Michigan CF NBS program decided to recommend that clinicians monitor infants with very high IRT $(\geq 99.8 \%)$ and no identified CF mutations for clinical symptoms of CF instead of referring them for sweat testing.

Michigan decided not to repeat the IRT test at a later date, as is done in some states, because IRT concentrations appear to decline over time in both cases and non-cases alike. ${ }^{18}$ Rock et al. ${ }^{18}$ reported in 1990 that after excluding meconium ileus patients and four infants with falsenegative screening results, $27 \%$ of 33 infants with CF had IRT values fall below their cutoff on a second specimen. However, while Rock et al.'s findings are specific to repeat specimens collected at 40-100 days of life meaning they may not be generalizable to repeat specimens collected a few weeks after birth. Limitations of Rock et al.'s study noted, we feel that further study is needed prior to consideration of an IRT/DNA/IRT protocol in Michigan. Our study further indicates that unless IRT percentiles are adjusted, the group of infants having high IRT concentrations ( $\geq 99$.8th percentile) and no CF mutation(s) are at very low risk of the disease overall, meaning the probability that a repeat IRT test would identify a CF case in this group is extremely low.

Our results also indicate that unadjusted percentile cutoffs are influenced by the proportions of blacks, low birth weight and preterm infants meaning the greater the proportions the greater the unadjusted percentile cutoffs. Thus, Michigan's 96th percentile IRT cutoff value is likely greater than in states with fewer blacks, such as Wisconsin, meaning it may be worthwhile to investigate whether reduction of the percentile cutoff or variation in the method of calculation would increase detection in Michigan. Our results also suggest that states employing an initial IRT cutoff above the 96th percentile may also want to re-evaluate their algorithm given that we have detected cases close to our initial cutoff. Cutoffs could either be lowered or the method of calculation could be revisited. For instance, NBS could explore various methods of defining and removing outliers prior to IRT percentile cutoff calculation. Further study is necessary to determine if cutoff reevaluation is necessary; these studies should be conducted by NBS programs serving large populations that have a sound mechanism for detection of false negatives.

Our results may be impacted by missing or inaccurate data; however, there is no indication that reporting of demographics or perinatal information on the NBS card is differential by IRT concentration. Due to poor data quality, we were unable to assess variation in IRT concentrations by Hispanic ethnicity. Our study is also limited in that it reports results of only 1 year of CF screening which particularly inhibits assessment of potentially false negative screening results given CF symptom onset and diagnosis unrelated to NBS occurs later, mostly beyond one year of age. No false negatives have been reported thus far in Michigan, although because passive surveillance is the method of ascertainment there could be undetected cases. Finally, our results are specific to Michigan's population, meaning our findings may not be generalizable to other states and the greater United States.

In conclusion, we recommend that NBS programs that still make positive screening determinations based on high IRT alone reconsider this practice. We recommend careful consideration of the potential ramifications and utility, if any, of adjusting IRT percentile-based cutoffs. We suggest that if adjustment is deemed desirable then gestational age or birth weight be considered as optimal adjustment factors. It may also be prudent to re-evaluate initial IRT cutoff values given that we have detected several $\mathrm{CF}$ cases near our 96th percentile cutoff and some states employ an initial cutoff greater than our 96th percentile. Further research is necessary to confirm our findings; we recommend these studies be conducted by longstanding CF NBS programs that have a greater number of detected cases and an active mechanism to detect false negative screens. 


\section{ACKNOWLEDGMENTS}

We would like to acknowledge the Michigan Cystic Fibrosis Newborn Screening Research Subcommittee for their support of this project. The lead author now works for MPRO in Farmington Hills, Michigan.

\section{REFERENCES}

1. Welsh MJ, Ramsy BW, Accurso F, Cutting GR. Cystic fibrosis. In: Scriver CR, Beaudet AL, Sly WS, Valle D, editors. The metabolic and molecular basis of inherited disease. 8th edition. New York, NY: McGraw-Hill; 2001. 5121-5188.

2. Crossley JR, Elliott RB, Smith PA. Dried-blood spot screening for cystic fibrosis in the newborn. Lancet 1979;1:472-474.

3. Grosse SD, Boyle CA, Botkin JR, Comeau AM, Kharrazi M, Rosenfeld M, Wilfond BS. Newborn screening for cystic fibrosis: evaluation of benefits and risks and recommendations for state newborn screening programs. MMWR Recomm Rep 2004;53: $1-36$.

4. Grosse SD, Rosenfeld M, Devine OJ, Lai HJ, Farrell PM. Potential impact of newborn screening for cystic fibrosis on child survival: a systematic review and analysis. J Pediatr 2006;149: 362-366.

5. American College of Medical Genetics Newborn Screening Expert Group. Newborn screening: toward a uniform screening panel and system-executive summary. Pediatrics 2006;117: S296-S307.

6. Cheillan D, Vercherat M, Cheavlier-Porst F, Charcosset M, Rolland MO, Dorche C. False positive results in neonatal screening for cystic fibrosis based on a three-stage protocol (IRT/DNA/IRT): should we adjust IRT cut-off to ethnic origin? J Inherit Metab Dis 2005;28:813-818.

7. Kloosterboer M, Hoffman G, Rock M, Gershan W, Laxova A, Li Z, Farrel PM. Clarification of laboratory and clinical variables that influence cystic fibrosis newborn screening with initial analysis of immunoreactive trypsinogen. Pediatrics 2009;123: e338-e346.

8. Giusti R, New York State Cystic Fibrosis Newborn Screening Consortium. Elevated IRT levels in African-American infants: implications for newborn screening in an ethnically diverse population. Pediatr Pulmonol 2008;43:638-641.
9. Gregg RG, Simante A, Farrell PM, Koscik R, Kosorok MR, Laxova A, Laessig R, Hoffman G, Hassemer D, Mischler EH, Splaingard M. Newborn screening for cystic fibrosis in Wisconsin: comparison of biochemical and molecular methods. Pediatrics 1997;99:819-824.

10. Herson VC, LaFreniere J. Elevated immunoreactive trypsinogen (IRT) in premature infants. Pediatric Pulmonol 1999;28. 214A.

11. Rock MJ, Mischler EH, Farrell PM, Bruns WT, Hassemer DJ, Laessig RH. Immunoreactive trypsinogen screening for cystic fibrosis: characterization of infants with a false-positive screening test. Pediatr Pulmonol 1989;6:42-48.

12. Tluczek A, Koscik RL, Farrell PM, Rock MJ. Psychosocial risk associated with newborn screening for cystic fibrosis: parents' experience while awaiting the sweat-test appointment. Pediatrics 2005;115:1692-1703.

13. Brooks K, Chik L, O'Brien JE, Ayoub M, Johnson MP, Evans MI. Variability of adjustments to indices in determining patient risk in biochemical screening. Fetal Diagn Ther 1999;14:42-46.

14. Grosse SD, Olney RS, Baily MA. The cost effectiveness of universal versus selective newborn screening for sickle cell disease in the US and the UK: a critique. Appl Health Econ Health Policy 2005;4:239-247.

15. Rock MJ, Hoffman G, Laessig RH, Kopish GJ, Litsheim TJ, Farrell PM. Newborn screening for cystic fibrosis in Wisconsin: nine-year experience with routine trypsinogen/DNA testing. J Pediatr 2005;147:S73-S77.

16. Comeau AM, Parad RB, Dorkin HL, Dovey M, Gerstle R, Haver K, Lapey A, O'Sullivan BP, Waltz DA, Zwerdling RG, Eaton RB. Population-based newborn screening for genetic disorders when multiple mutation DNA testing is incorporated: a cystic fibrosis newborn screening model demonstrating increased sensitivity but more carrier detections. Pediatrics 2004;113:1573-1581.

17. Giusti R, Badgwell A, Iglesias AD, New York State Cystic Fibrosis Newborn Screening Consortium. New York State cystic fibrosis consortium: the first 2.5 years of experience with cystic fibrosis newborn screening in an ethnically diverse population. Pediatrics 2007;119:e460-e467.

18. Rock MJ, Mischler EH, Farrell PM, Wei LJ, Bruns WT, Hassemer DJ, Laessig RH. Newborn screening for cystic fibrosis is complicated by age-related decline in immunoreactive trypsinogen levels. Pediatrics 1990;85:1001-1007. 